and nursing. It is written by a psychiatrist who has the gift of lucidity and who possesses sound judgment. It affords an excellent opportunity for the medical student to supplement his otherwise meagre training in psychological medicine, can be highly recommended for the postgraduate who is not an expert in this specialty and mental nurses will benefit in particular by the advice given on general psychiatric nursing and on special procedures.

All such readers will find that Dr. Stallworthy's aim to present ' a practical account of what is likely to matter to them' has been admirably achieved. They must remember, however, that there is an additional unmentioned aspect of growing importance, namely, community care.

\section{DOCTORS' COMMONS-A SHORT HISTORY , OF THE BRITISH MEDICAL ASSOCIATION}

By Paul Vaughan. Pp. xvi $+254,30$ illustrations.

London: William Heinemann Ltd. I959. I 8s.

The life and work of Dr. Charles Hastings are well known to all genuine students of the history of medicine, and have been the subject of numerous lectures and writings by medical authors. Hastings's pioneer work in founding the original society which subsequently became the British Medical Association, the present status of which he could not have foreseen, must be classed among the most inspiring examples of the triumph of the virtues of persistence and faith over obstacles raised by prejudice and jealousy. Mr. Vaughan's book tells of this triumph and gives an excellent account of the development of the B.M.A. from its very beginning up to the present day. 'Doctors' Commons' differs from most works to be found in libraries of medical historians in that it is addressed as much to the lay public as to medical men, and we think it should have a genuine appeal to the former, no less than to the latter. We were especially pleased to read the excellent preamble which describes and corrects the misconceptions entertained by most of the lay public in regard to the nature and functions of the B.M.A. Any non-medical reader of this volume-and we hope there will be many-should read, mark, learn and inwardly digest this most useful and informative introduction.

It is no easy matter to sort out and arrange a vast mass of medical and historical detail and to set down the results of such labour in concise form. Nor indeed is it easy to combine accuracy of historical narrative with a literary style which will make a book attractive to its readers and free from any suspicion of dullness. Mr. Vaughan has the happy knack of achieving these objects and upon his skill in accomplishing the task he is to be congratulated.

Not least among the attractions of the book are its illustrations, which include not only portraits of many of the chief characters in the story but also several reproductions of Punch cartoons, as apposite as they are entertaining. The problem of selection of the most appropriate pictures from a large amount of available matter must have called for much care and discrimination, and here again the author is to be congratulated.

The format of the volume is good; the print is of good size and is kind to the eye; the book is convenient size and easy to hold. We regard it as a real addition to our literature, and we wish it success.

\section{ACTA PSYCHIATRICA ET NEUROLOGICA SCANDINAVICA}

Involutional Melancholia: An etiological, clinical and social study of endogenous depression in later life, with special reference to genetic factors

By Ake Stenstedt, M.D. Supplement 127, Vol.

34. Copenhagen: Ejnar Munksgaard. I 959.

In Sweden information relevant to statistical, genetic and social studies on psychiatric disabilities can be obtained not only from the usual channels, but also by reference to parish registers. They contain data on cases of mental illness or abnormality which have arisen in the specified area and Dr. Stenstedt's work shows their value when coupled with a review. of hospital case-records, follow-up and personal contact with many families.

This investigation includes material obtained from two mental hospitals and two other clinics in Stockholm, from Gothenburg and from another Swedish county. The final total with sibs and parents was 2,282 persons, of whom 307 were probands. Sub-grouping of depressive states presents difficulties and this is especially so with the more recent trend of thought that depression previously classified as endogenous may in some cases be mainly exogenous. This research is therefore all the more commendable.

After a detailed description of the material investigated, the methods used and the principles of diagnosis there follows a text (supported by I I tables) which requires concentrated study, and five appendices. New facts have emerged, as also some interesting probabilities.

\section{THE EFFECT OF PHARMACOLOGIC AGEINTS} ON THE NERVOUS SYSTEM

\section{Research Publications, Association for} Research in Nervous and Mental Disease Vol. 37

Edited by Francis J. Braceland, M.D. Pp. xi + 488, I 24 illustrations. London: Bailliére, Tindall \& Cox Ltd. I959. I08s.

A glance at the list of publications of the Association shows that this body has been responsible since I 920 for presenting very recent, often pioneering knowledge in book form. The 37 th volume contains the proceedings of a conference in December, I957, dealing with the present status of neuro- and 
psychopharmacology. Amongst the 26 chapters, general reviews, accounts of clinical experiences, more elaborate clinical studies, and reports on experimental work of various degrees of complexity may be found.

The chapters surveying present knowledge cover the treatment of infections of the nervous system with vaccines, sera and antibiotics, anticonvulsants, drugs used in Parkinsonism and other movement disorders, metabolic defects affecting the central nervous system, hormonal factors-particularly adrenal and thyroid-in psychoses, reserpine, phenothiazines, iproniazid, drug addiction, and opiate antagonists. The topics are dealt with in varying detail. The brief and basic approach used in some of these chapters seems unusual for a gathering of specialized workers.

In most cases, reports on individual research accompany the reviewing contributions. Drs. D. M. Woodbury and D. W. Esplin describe work on the metabolism and pharmacodynamics of anti-convulsant drugs. Dr. K. R. Unna and his colleagues present further evidence in favour of the selective inhibition of spinal interneurones by mephenesin and SKF 1045. Two very instructive chapters by Drs. J. V. Brady and H. E. Lehmann discuss methodological points in the evaluation of drug effects on human and animal behaviour, respectively. They are followed by Dr. S. Wolf's cautionary essay on placebos. The story of 2-dimethylaminoethanol, a presumed precursor of acetylcholine and a central stimulant, is traced from animal experiments to clinical trials in schizophrenics by Drs. H. B. Murphree, E. H. Jenney and C. C. Pfeiffer. EEG studies of the action of phenothiazines are described by Drs. E. K. and K. F. Killam, and of nervous stimulants (here differentiated into energizers and anti-depressants) by Dr. H. E. Himwich. The two articles require careful reading but they repay the effort by giving an insight into the possibilities of EEG techniques even to readers not familiar with the method. A very thoroughly documented and illustrated account of the structural effects of tranquillizers is given by Drs. L. Roizin, C. True and M. Knight. Dr. L. Lasagna has taken up the problem of ' misinformation amongst physicians, perpetuated by textbooks and teaching with regard to hypnotics and sedatives. His own large scale observations and those collected from other doctors have brought him to conclusions which ' disagree with most textbooks.' Dr. L. G. Abood reports further instances of increased ceruloplasmin levels in nervous disease. He has also isolated an unstable adrenaline metabolite which produces psychotic symptoms in animals. Another plasma fraction is blamed for psychotic effects by Dr. R. G. Heath and his group. It has been given the euphonious name 'taraxein,' and produced schizophrenic symptoms in volunteering prisoners and monkeys. The discussions which follow these bold hypotheses are less aggressive than one would have feared. An impressive attempt to explain drug effects at the level of neuro-cellular chemistry and microstructure is made by Drs. R. G. Grenell, L. May, W. D.气 McElroy and J. Mendelson. The series is con- 3 cluded by Dr. T. R. Robie's hopeful report on the $\stackrel{\AA}{\varrho}$ use of iproniazid in melancholia.

The discussions of papers are an integral and $\vec{\Rightarrow}$ useful part of books of this type. In this volume chapters are often discussed in groups, which means? that pertaining remarks have to be located in some cases.

\section{ANESTHESIA FOR INFANTS AND CHILDREN}

By Robert M. Smith, M.D. Pp. 418. St. Louis : $\overrightarrow{\vec{\omega}}$ The C. V. Mosby Co. Distributed in Great Britain by Henry Kimpton, London. 90 s.

Dr. Smith's extensive experience of paediatric anaesthesia has enabled him to write a valuable work on the subject. Practically every aspect of ${ }_{A}^{\circ}$ the management of these small patients is discussed $\vec{\omega}$ in detail, emphasis being rightly placed on the $\tilde{O}$ importance of a sound knowledge of infant and child physiology. Prominence is also given to descrip- $-\dot{\sigma}$ tions of disease processes and their implications too the anaesthetist; indeed, this is a particularly. pleasing aspect of the book that is likely to prove ${ }_{z}$ very helpful to the reader seeking knowledge of lesso commonly performed operations. So far as anaesthesia is concerned, Dr. Smith's preference for inhalational anaesthesia in a closed system and wio spontaneous respiration predominates, while treo use of muscle relaxants with controlled respirat receives less favour than it would perhaps fromo a British author. These pages do, however, containmuch excellent practical advice on the art of anaesthesia and, after reading them, few will beo able to doubt the importance of special experience in this interesting branch of anaesthesia. This is an excellent book, well produced and amply응 illustrated and can be thoroughly recommended

\section{FORENSIC MEDICINE, OBSERVATION AND INTERPRETATION}

By A. KeIth Mant, M.D.(Lond.). Pp. $262 \frac{3}{3}$. London: Lloyd Luke Ltd. I 959. $42 \mathrm{~s}$.

There are already three Scottish, four English and a number of American works on legal medicine, and publishers who are business men must have been persuaded that Mant had something in theo nature of 'a new work' on the subject before. accepting it. He has, for this little book makes ano entirely practical approach, confining itself to the duties of the doctor, police or coroner's officer and C.I.D. man ' at the scene.' 'Observation and Interpretation' are indeed its key notes, and the author has managed to adhere strictly to the tasko he set for himself. This is a concise, practical ando well illustrated survey from a man of considerable experience of the approach to the body in cases of suspicious or violent death-and in sex offences $\overline{\mathrm{O}}$ what to look for and what to say in order to give the 